\title{
Determining nitrogen deficiencies for maize using various remote sensing indices
}

\author{
Brayden W. Burns ${ }^{1} \cdot$ V. Steven Green ${ }^{2,3}$ (D) Ahmed A. Hashem ${ }^{2,3}$ (D) \\ Joseph H. Massey ${ }^{4}$ (D) Aaron M. Shew ${ }^{2,5,6}$ (D) M. Arlene A. Adviento-Borbe ${ }^{4}$ (i) . \\ Mohamed Milad ${ }^{7}$
}

Accepted: 11 October 2021 / Published online: 1 January 2022

(C) The Author(s) 2021

\begin{abstract}
Determining a precise nitrogen fertilizer requirement for maize in a particular field and year has proven to be a challenge due to the complexity of the nitrogen inputs, transformations and outputs in the nitrogen cycle. Remote sensing of maize nitrogen deficiency may be one way to move nitrogen fertilizer applications closer to the specific nitrogen requirement. Six vegetation indices [normalized difference vegetation index (NDVI), green normalized difference vegetation index (GNDVI), red-edge normalized difference vegetation index (RENDVI), triangle greenness index (TGI), normalized area vegetation index (NAVI) and chlorophyll index-green $\left(\mathrm{CI}_{\text {green }}\right)$ ] were evaluated for their ability to detect nitrogen deficiency and predict grain maize grain yield. Strip trials were established at two locations in Arkansas, USA, with nitrogen rate as the primary treatment. Remote sensing data was collected weekly with an unmanned aerial system (UAS) equipped with a multispectral and thermal sensor. Relationships among index value, nitrogen fertilizer rate and maize growth stage were evaluated. Green NDVI, RENDVI and $\mathrm{CI}_{\text {green }}$ had the strongest relationship with nitrogen fertilizer treatment. Chlorophyll Index-green and GNDVI were the best predictors of maize grain yield early in the growing season when the application of additional nitrogen was still agronomically feasible. However, the logistics of late season nitrogen application must be considered.
\end{abstract}

Keywords Nitrogen deficiency $\cdot$ Remote sensing $\cdot$ Conservation agriculture $\cdot$ Vegetation index $\cdot$ UAS $\cdot$ Drone

\section{Introduction}

Intensive maize production often necessitates external nitrogen inputs. Approximately 5.5 Mt of nitrogen was applied to maize (Zea mays L.) in the United States in 2018 (USDAERS, 2019). Despite high N-demand, determining precise nitrogen fertilizer requirements for maize has proven to be a challenge due to the complexity of the nitrogen cycle (Morris

V. Steven Green

sgreen@astate.edu

Extended author information available on the last page of the article 
et al., 2018). In Arkansas, as well as many other states, N-rates are established using two factors: maize grain yield goal and soil texture. For example, maize grown on silty or sandy loam soils with a grain yield goal of $11 \mathrm{t} \mathrm{ha}^{-1}$ will require $247 \mathrm{~kg} \mathrm{~N} \mathrm{ha}^{-1}$ (Espinoza \& Ross, 2012; Morris et al., 2018). However, it is well documented that no-tillage and winter cover crops can significantly alter nitrogen dynamics within an agroecosystem (Doran, 1987; Kaspar et al., 2012; Kuo et al., 2001; Mahal et al., 2018; Tonitto et al., 2006). As a result, N-recommendations based on conventional systems may not be applicable under the agricultural practices of no- or minimal tillage, winter cover crops and/or diverse crop rotations.

Unmanned aerial systems (UAS), which have demonstrated a wide range of capabilities, may be a valuable management asset. Gautam and Pagay (2020) found that UAS-derived data were not as impacted by cloud cover and had higher spatial and temporal resolution than satellite-based imagery. Although UAS are limited in terms of sensor size and range, they are also simpler, more cost effective and have fewer safety constraints than manned systems. Unlike ground-based sensors, aerial platforms facilitate rapid, whole-field assessments with a greater number of observations.

The broad agronomic capabilities of UAS can be summarized into three basic categories: scouting areas where issues are suspected, in-season crop monitoring and nutrient management (Hunt \& Daughtry, 2018). Although the selective scouting of problem areas is feasible, farm-scale crop monitoring remains economically and logistically constrained by costs associated with data processing and management (Hunt \& Daughtry, 2018). Nevertheless, the ability to quickly detect and geo-reference maize $\mathrm{N}$-deficiencies during critical growth stages through optical-sensors has significant management implications (Dhital \& Raun, 2016; Gabriel et al., 2016).

Using remote sensing technology, nitrogen, phosphorus, potassium and sulfur deficiencies have been successfully identified in wheat (Mahajan et al., 2014), and the association of various vegetation indices with nitrogen supply and plant chlorophyll content is well documented (Dellinger et al., 2008; Hunt, et al., 2013; Maresma et al., 2018; Preza Fontes et al., 2019). Furthermore, remote sensing-based nitrogen recommendations for maize have been suggested in prior studies (Clay et al., 2006; Dellinger et al., 2008; Schmidt et al., 2009). Although nutrient management through remote sensing has proved promising, there are a multitude of possible indices that could be used to assess nitrogen stress.

Of the following indices assessed, normalized difference vegetation index (NDVI) is one of the oldest and has been used extensively for a myriad of applications (Rouse et al., 1974). Because NDVI is associated with plant health, it has a significant relationship with early-season $\mathrm{N}_{2} \mathrm{O}$ emissions when low crop demand exacerbates $\mathrm{N}$ losses (Preza Fontes et al., 2019). Due to its relationship with leaf area index (LAI), NDVI may lose predictive power once the canopy has closed around V9 (9 true, collared leaves; Teal et al., 2006). Loss of sensitivity after canopy closure can reduce the usefulness of NDVI later in the season. However, NDVI can remain sensitive until reproductive stages if LAI remains less than 4 (Hatfield \& Prueger, 2010).

Triangle greenness index (TGI) was developed by Hunt et al. (2013) as a novel chlorophyll index and potential tool for $\mathrm{N}$-management. The index was found to be insensitive to LAI above 2.0 while retaining a high correlation with plant chlorophyll concentration (Hunt et al., 2013). However, TGI based N-sufficiency classification was not found to be superior to manual color (i.e., chart based) classification (Friedman et al., 2016).

Like TGI, the normalized area vegetation index (NAVI) was intended to have a strong correlation with leaf chlorophyll concentration. This index simplifies the normalized area over reflectance curve (NAOC), which is a hyperspectral index (Carmona et al., 
2015). Chlorophyll concentration and NAOC share a strong relationship. Across a widerange of horticultural and agronomic crops, a coefficient of determination $\left(\mathrm{R}^{2}\right)$ of 0.79 and root mean square error (RMSE) of $10 \mu \mathrm{g} \mathrm{cm} \mathrm{cm}^{-1}$ was obtained using satellite-based sensors (Delegido et al., 2011). Crops in this 2011 study included sunflower (Helianthus annuus), fruit trees, alfalfa (Medicago sativa), maize, garlic (Allium sativum), grapes (Vitis vinifera), onion (Allium cepa), potato (Solanum tuberosum), almond (Prunus dulcis), oats (Avena sativa), wheat (Triticum aestivum), barley (Hordeum vulgare), Fescue (Festuca) and bare soil. Furthermore, NAVI was found to have a very high correlation with NAOC across several remote sensing platforms (Carmona et al., 2015).

Chlorophyll index green $\left(\mathrm{Cl}_{\text {green }}\right)$ and chlorophyll index red edge $\left(\mathrm{CI}_{\text {red-edge }}\right)$ were also developed to model canopy chlorophyll concentration via remote sensing (Gitelson et al., 2005). At high chlorophyll concentrations, simple reflectance becomes saturated and increasing chlorophyll concentration has little effect on simple reflectance. However, algorithms based on more sensitive wavelengths (e.g., green and red), and stable wavelengths (e.g., near infrared (NIR)) can overcome this limitation (Gitelson \& Merzlyak, 1994, 1997; Gitelson et al., 2003). Chlorophyll index green and $\mathrm{CI}_{\text {red-edge }}$ operate on these premises with the explicit goal of sensing chlorophyll concentration.

In a midwestern soybean (Glycine max)-maize rotation, $\mathrm{CI}_{\text {green }}$ and $\mathrm{CI}_{\text {red-edge }}$ were found to have strong, linear relationships with canopy chlorophyll concentration (Gitelson et al., 2005). Reese et al. (2010) found that $\mathrm{CI}_{\text {green }}$ was positively correlated with yield loss due to nitrogen stress in hard red spring wheat (Triticum aestivum) In the same study, $\mathrm{CI}_{\text {green }}$ was negatively correlated with water stress, suggesting that chlorophyll indices could be used to differentiate between $\mathrm{N}$-stress and water-stress (Reese et al., 2010). Chlorophyll index green and GNDVI were both found to have higher $\mathrm{R}^{2}$ values and higher saturation points than NDVI at the V12 growth stage in maize. Vegetation indices that use green bands tend to have an improved potential for determining optimum $\mathrm{N}$-rates for grain yield relative to indices that are dependent on red bands (Maresma et al., 2018). Hatfield and Prueger (2010) suggest that $\mathrm{CI}_{\text {green }}$ could be used during early stages of crop development.

By combining stable and dynamic wavelengths, GNDVI operates on the same principles as the preceding indices. What distinguishes GNDVI from $\mathrm{CI}_{\text {green }}$ and $\mathrm{CI}_{\text {red-edge }}$ is that GNDVI is normalized; its values are constrained to a set range of possible values. Gitelson and Merzlyak, (1997) also noted that GNDVI is compatible with a large range of leaf pigmentations. Green NDVI has also been found to have a stronger relationship with maize grain yield than NDVI (Shanahan et al., 2001). In maize, GNDVI can be a good predictor of the economic optimum nitrogen rate (EONR) given a reference plot and the absence of pre-plant N-fertilization at the V6 to V7 growth stage (Dellinger et al., 2008). Using an active light, on-the-go sensor, GNDVI can predict maize EONRs with precision similar to traditional N-recommendation methods (soil or plant analysis, pre-sidedress nitrate test, corn stalk nitrate test; Schmidt et al., 2009).

Red-edge NDVI is computationally similar to GNDVI except it uses reflectance in the red-edge rather than the green band. Red-edge NDVI was found to have a stronger relationship with maize grain yield than NDVI, particularly when reflectance data were collected later in the season (Preza Fontes et al., 2019; Sharma et al., 2015). Additionally, RENDVI is more sensitive to chlorophyll concentration than traditional NDVI because NDVI is determined by the ratio of exposed leaf to soil surface (Sharma et al., 2015). Interestingly, NDVI was found to have a stronger relationship with maize biomass and nitrogen uptake than RENDVI, but maize grain yield had a stronger relationship with RENDVI than NDVI (Preza Fontes et al., 2019). 
Cumulatively, remote sensing apparatuses coupled with an appropriate index have demonstrated an acute ability to quickly assess plant growth and development. Evaluating crop $\mathrm{N}$-demand through remote sensing indices is by no means a novel proposition (Clay et al., 2006; Sharma et al., 2015). However, considerable ambiguity remains concerning index selection and practical constraints. Although general adoption may currently be unrealistic, rapidly developing UAS, sensor and data processing technology attests to a quickly developing potential (Hunt \& Daughtry, 2018). This potential is especially high in conservation systems where farmers wish to evaluate in-season changes to soil-N supply (Dhital \& Raun, 2016; Gabriel et al., 2016).

The goal of this study was to determine the relationships among nitrogen fertilizer rates, maize grain yield, maize growth stage and an assortment of vegetation indices (TGI, NAVI, $\mathrm{CI}_{\text {green }}$, GNDVI, RENDVI and NDVI; Table 1). The specific objectives of this study were to determine: (i) the strengths and weaknesses of vegetation indices in detecting nitrogen fertilizer treatments, (ii) the effect of maize growth stage on the relationship between vegetation index and nitrogen treatment, and (iii) the power of vegetation indices for predicting maize grain yield during vegetative and reproductive growth stages.

\section{Methods}

Research sites with a history of no-tillage and winter cover crops were established on commercial farms at Cotton Plant $\left(35^{\circ} 00^{\prime \prime} \mathrm{N}, 91^{\circ} 17^{\prime \prime} \mathrm{W}, 60 \mathrm{~m}\right.$ elevation) and Helena $\left(34^{\circ} 30^{\prime \prime} \mathrm{N}\right.$, $90^{\circ} 38^{\prime \prime} \mathrm{W}, 58 \mathrm{~m}$ elevation), Arkansas, USA. The soil type at Helena was a Convent silt loam (Coarse-silty, mixed, superactive, nonacid, thermic Fluvaquentic Endoaquepts; USDA-NRCS, 2013). The soil at Cotton Plant was a Teksob loam (Fine-loamy, mixed, active, thermic Typic Hapludalfs; USDA-NRCS, 2019). The experimental design consisted of three randomized blocks each containing eight nitrogen rates with winter cover crops present. The $\mathrm{N}$-rate treatments $\left(0,62,124,185,247\right.$ and $\left.309 \mathrm{~kg} \mathrm{~N} \mathrm{ha}^{-1}\right)$ represented 0,25 , $50,75,100$ and $125 \%$, respectively, of the University of Arkansas' recommended N-rate (247 $\mathrm{kg} \mathrm{N} \mathrm{ha}^{-1}$ ) for maize (Espinoza \& Ross, 2012).

\section{Management practices}

Winter cover crop mixes, $\mathrm{N}$-fertilizer types and application timings, planting and harvesting dates, maize hybrid and crop rotation sequences were all provided by cooperating farmers (Table 2). Weather for the 2019 growing season was obtained from NOAA (Table 3). Sites were managed following conservation agriculture practices common to eastern Arkansas. Furrow irrigation was applied using lay-flat plastic tubing (Delta Plastics, Little Rock, AR, USA). Water stress was not observed at any site and, therefore, was not considered in these analyses.

\section{Remote sensing and data extraction}

Remote sensing data were collected with a 7-day temporal resolution at Cotton Plant, Arkansas, and a 30-day temporal resolution at Helena, Arkansas. The Cotton Plant site was the focus of this study with high temporal resolution, while the Helena site was used as a secondary site with less temporal resolution. Furthermore, some of the remote sensing data from the Helena site was compromised due to stitching errors. Maize growth stage 


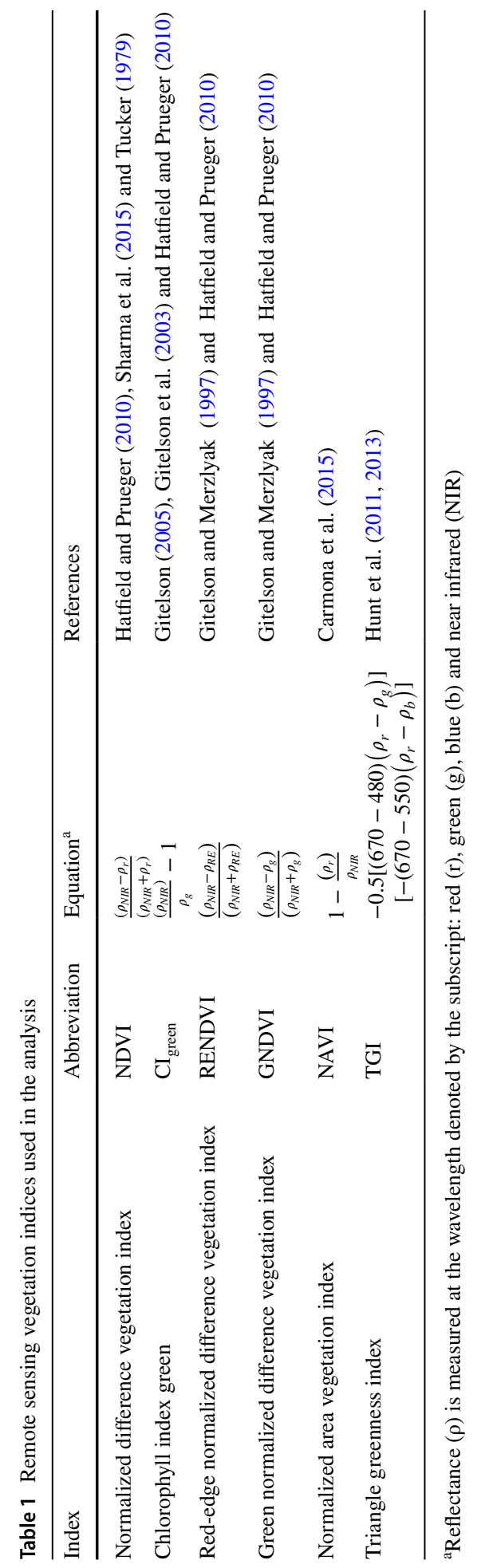


Table 2 Management practices at the Cotton Plant and Helena sites during the 2019 growing season

\begin{tabular}{|c|c|c|}
\hline Variable & Date & Description \\
\hline \multicolumn{3}{|l|}{ Cotton Plant } \\
\hline Prior crop & - & Soybean \\
\hline Cover crop termination & 23 March & $\begin{array}{l}\text { Black oat (Avena strigosa), } \\
\text { winter pea (Pisum sativum) } \\
\text { and radish (Raphanus sativus) }\end{array}$ \\
\hline Planting & 01 May & Twin row maize, $\mathrm{BH} 8700 \mathrm{VT} 2 \mathrm{P}$ \\
\hline Population (plant ha ${ }^{-1}$ ) & - & 80000 \\
\hline Pre-plant $\mathrm{N}$-application & 26 March & Broadcast ammonium sulfate ${ }^{\mathrm{d}}$ \\
\hline Post-VE N-application & 04 June & Broadcast urea \\
\hline Harvest & 04 Oct & - \\
\hline \multicolumn{3}{|l|}{ Helena } \\
\hline Prior crop & - & Maize \\
\hline Cover crop termination & 06 April & $\begin{array}{l}\text { Cereal rye (Secale cereale), } \\
\text { Austrian winter pea (Pisum } \\
\text { sativum ssp. arvense) }\end{array}$ \\
\hline Planting & 27 April & DKC67-72 \\
\hline Population (plant ha ${ }^{-1}$ ) & - & 86000 \\
\hline Pre-plant N-application & 23 May & Sidedress, UAN 28-0-0-5 \\
\hline Post-VE N-application & - & None \\
\hline Harvest & $23 \mathrm{Aug}$ & - \\
\hline
\end{tabular}

(Table 4) was determined from randomly selected samples near the time of each flight to determine the effect of maize growth stage on vegetation index value and model uncertainty. A UAS (Matrice $210 \mathrm{~V}-2$ quadcopter, DJI, Shenzhen, China) was equipped with an Altum multispectral/thermal sensor (MicaSense, Seattle, WA, USA) to collect near infrared (NIR, $840 \mathrm{~nm})$, red edge (RE, $717 \mathrm{~nm})$, red $(\mathrm{R}, 668 \mathrm{~nm})$, green $(\mathrm{G}, 560 \mathrm{~nm})$ and blue $(\mathrm{B}, 475 \mathrm{~nm})$ reflectance data (MicaSense, 2020). Data collection occurred within two hours of solar noon. Prior to each flight, calibration images were collected with a calibrated reflectance panel and downwelling light sensor (MicaSense, Seattle, WA, USA).

To maintain a 75\% front/side overlap, flight plans were developed using the Atlas Flight application (MicaSense, Seattle, WA, USA). The UAS collected imagery at $120 \mathrm{~m}$ above ground level (AGL) while traveling at a horizontal velocity of $10 \mathrm{~m} \mathrm{~s}^{-1}$. Flight-design parameters were determined using the MicaSense flight calculator. Pix4D Mapper (Pix4D Inc., Prilly, Switzerland) and (Agisoft LLC, St. Petersburg, Russia) were used to stitch images together and create a geo-tiff file.

Multiple stitching programs were used to convert raw images into geo-tiff files for two reasons. First, geo-tiff files created by Pix-4D are substantially larger than geo-tiff files obtained through Agisoft. Although the higher resolution from Pix-4D was beneficial in some instances, it generally did not justify the substantially larger file sizes. Whenever possible, Agisoft was used to conserve data storage space. Second, when one method failed to stitch images, a geo-tiff file could often still be obtained through the other program. By using both stitching programs, file size was controlled and the number of stitching errors was reduced.

Whole-plot yield $\left(\mathrm{t} \mathrm{ha}^{-1}\right)$ was compared with the mean index value for each plot. The research design consisted of randomized blocks (Fig. 1), which allowed each flight to be evaluated separately. The relationship among index, grain yield, N-rate and timing (crop 
Table 3 Summary of rainfall and air temperature at Cotton Plant and Helena, Arkansas during the 2019 growing season

\begin{tabular}{lrlll}
\hline Month & $\begin{array}{l}\text { Precipitation } \\
(\mathrm{Mm})\end{array}$ & $\begin{array}{l}\text { Temperature minimum } \\
\left({ }^{\circ} \mathrm{C}\right)\end{array}$ & $\begin{array}{l}\text { Temperature maxi- } \\
\text { mum }\left({ }^{\circ} \mathrm{C}\right)\end{array}$ & $\begin{array}{l}\text { Temperature } \\
\text { mean }\left({ }^{\circ} \mathrm{C}\right)\end{array}$ \\
\hline Cotton Plant $^{\mathrm{a}}$ & & & & \\
March & 98.1 & 5.2 & 15.2 & 10.2 \\
April & 225.6 & 12.3 & 21.9 & 17.1 \\
May & 157.9 & 18.1 & 27.6 & 22.9 \\
June & 75.7 & 21.0 & 30.4 & 25.7 \\
July & 105.5 & 22.5 & 32.4 & 27.4 \\
August & 77.7 & 22.5 & 32.6 & 27.6 \\
September & 52.2 & 21.8 & 33.0 & 27.4 \\
October & 204.5 & 11.6 & 22.8 & 17.2 \\
Helena & & & & \\
March & 147.4 & 4.8 & 14.6 & 9.8 \\
April & 278.2 & 11.5 & 22.1 & 16.8 \\
May & 135.8 & 18.1 & 27.9 & 23.0 \\
June & 219.6 & 20.8 & 30.4 & 25.6 \\
July & 230.5 & 21.8 & 31.5 & 26.7 \\
August & 104.0 & 22.7 & 32.3 & 27.5 \\
September & 27.9 & 21.8 & 33.8 & 27.8 \\
October & 245.1 & 12.2 & 23.7 & 18.0 \\
\hline
\end{tabular}

${ }^{a}$ Cotton Plant data obtained from NOAA Des Arc weather station

${ }^{b}$ Helena data obtained from NOAA Helena weather station. Weather data was not available for the month of July 2019

${ }^{\mathrm{c}}$ July 2019 Helena weather data obtained from the nearby NOAA Marianna weather station (NOAA, 2020)

Planting and harvesting activities were performed using commercial farm equipment. As such, the widths of the research plots were dictated by the size of each farmers' equipment. Plots at Cotton Plant were 365 by $11.6 \mathrm{~m}$ on $0.96 \mathrm{~m}$ rows (twin-row planted). Plots at Helena were 550 by $13 \mathrm{~m}$ wide on $0.76 \mathrm{~m}$ rows. The center eight (Cotton Plant) or twelve rows (Helena) were harvested for grain yield. Grain yields were adjusted to $15.5 \%$ moisture content

Table 4 Maize vegetative and reproductive growth stages. Adapted from Ritchie and et al. (2008)

\begin{tabular}{ll}
\hline Vegetative growth stages & Reproductive growth stages \\
\hline VE emergence & R1 silking \\
V1 $^{\text {a }}$ first leaf & R2 blister \\
V2 second leaf & R3 milk \\
V3 third leaf & R4 dough \\
V(n) nth leaf & R5 dent \\
VT tasseling & R6 physiological maturity \\
\hline
\end{tabular}

${ }^{a}$ Each vegetative growth stage is identified by the uppermost leaf that is extended with the collar visible. A field or plot is designated at a particular growth stage when $>50 \%$ of the plants in that field are in or beyond that growth stage 

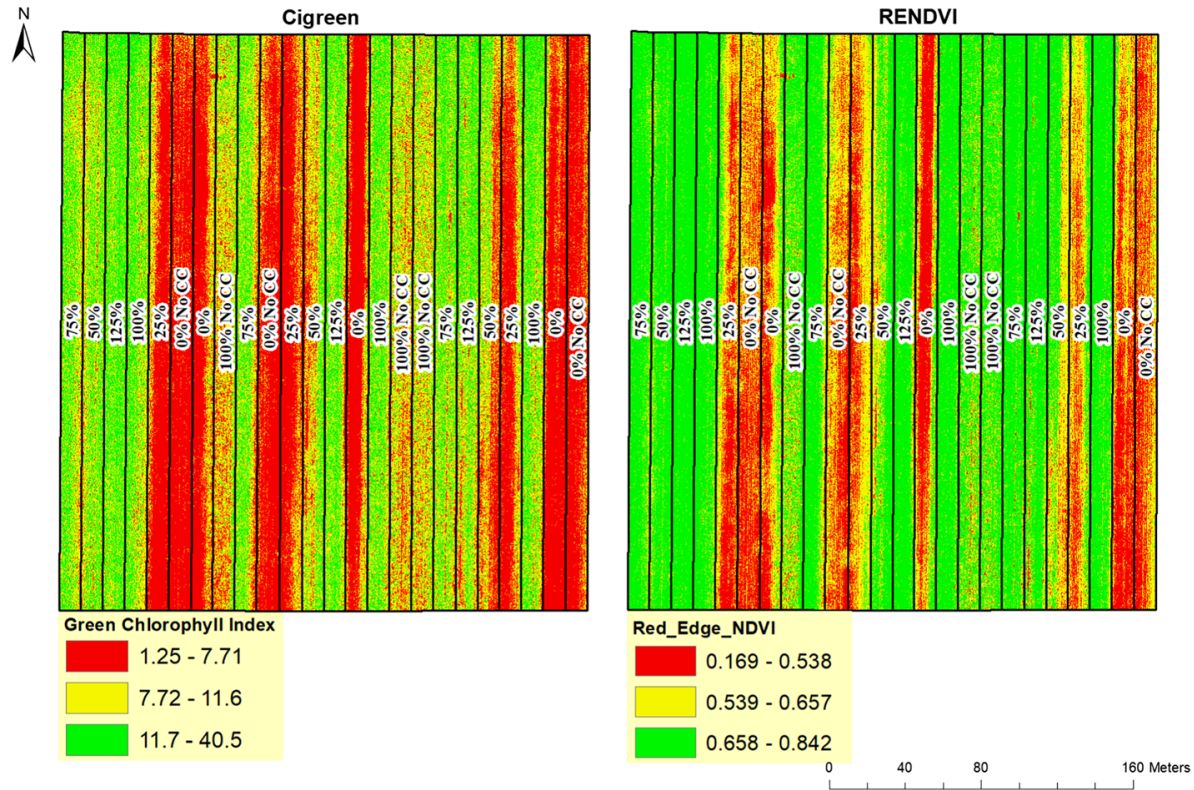

Fig. $1 \mathrm{CI}_{\text {green }}$ and RENDVI from the Cotton Plant site at the R2 growth stage. Green color in the map indicates high index values, yellow intermediate, and red low index values within three standard deviations of the site index mean. Image created using ArcMap (Color figure online)

growth stage) was analyzed on a per-plot, per-flight basis. A field scale spatial analysis was performed by comparing the average index value for each replicate, per flight and growth stage. ArcMap 10.7.1 (ESRI, Redlands, CA, USA) was used to calculate and extract the mean index value. A raster calculator was used to construct each index and a zonal statistic was used to calculate an average index value for each plot. Feature to point and point extraction tools were used to obtain the final vegetation index values (Fig. 2). Extraction shapefiles constructed for this process included a buffer at the top and bottom of the field to avoid turn rows (Fig. 1). Calibrated reflectance bands were used to calculate the NDVI, $\mathrm{CI}_{\text {green }}$, RENDVI, GNDVI, NAVI and TGI (Table 1).

\section{Statistical methods}

\section{Regression analysis}

All statistical analyses were performed using SAS statistical software (SAS University Edition, SAS Institute INC, Cary, NC, USA: Release 3.8, Version 9.4M6). Analysis of vegetation indices was limited to observations obtained between the V6 (six true, collared leaves) and R4 (dough formation) growth stages. This period of crop development was selected because it captured a wide range of maize $\mathrm{N}$-uptake while ignoring less active growth periods. Typically, $65 \%$ of total N-uptake occurs between V6 and vegetative tasseling (VT) (English et al., 2017). Approximately $20 \%$ of maize nitrogen demand is satisfied between VT and R3 (milk-like liquid present in kernels) with some uptake extending into later 


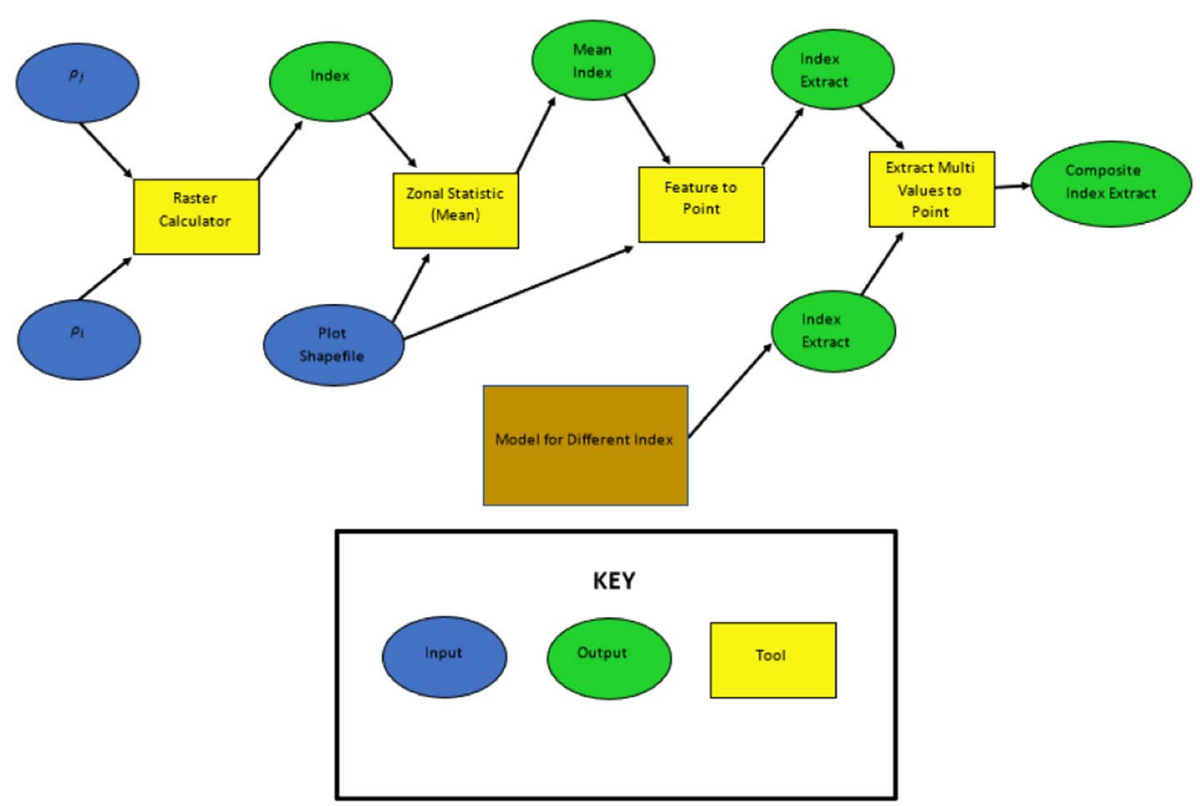

Fig. 2 Example of ArcGIS model used to calculate, extract and composite the mean index value for each plot. $\rho$ denotes reflectance at a given wavelength (i or $\mathrm{j}$ )

stages (English et al., 2017). Additionally, mid- to late-season analysis helps control for soil effects due to increased vegetative ground coverage and LAI.

Multiple linear regression was used to determine relationships for each index and maize growth stage and $\mathrm{N}$-fertilizer rate (Table 5). Polynomial terms were added to a model if they improved model fit (i.e. better met the assumptions of regression) or improved predictive power of the model. To avoid over-parameterization, only second-degree polynomials were used. The adjusted coefficient of determination $\left(\mathrm{R}_{\text {adj. }}^{2}\right)$ was used to evaluate the strength of these relationships. When the remote sensing index value was treated as the dependent variable, nitrogen rate and maize growth stage were included in the model as second-degree polynomials equation (1):

$$
Y_{i}=\beta_{0}+\beta_{1} x_{i N-\text { rate }}+\beta_{2} x_{i N-\text { rate }}^{2}+\beta_{3} x_{\text {istage }}+\beta_{4} x_{\text {istage }}^{2}+\varepsilon_{i},
$$

where $Y_{i}$ is the index value, $x_{i N \text {-rate }}$ is the nitrogen rate and $x_{i s t a g e}$ is the growth stage. Since the scope of this study was focused on large scale (large plot scale) analysis, the use of regression analysis was chosen, which inherently limits the analysis of temporal information and uncertainty of the model.

Simple linear regression was used to determine the six index relationships with maize grain yield (Table 6). Since the regression analysis was conducted on a plot basis, the spatial analysis was global and not site-specific. When predicting yield by remote sensing index values Eq. (2), terms related to maize growth stage were removed due to their high correlation with the index values. Each growth stage was analyzed separately, thereby avoiding multi-collinearity. As before, $\mathrm{R}^{2}$ was used to evaluate the strength of relationships between index values and grain yield. All yield regression analyses were performed using robust parameter estimates to 
Table 5 Index values modeled as a function of nitrogen rate and growth stage at the Cotton Plant and Helena study

\begin{tabular}{|c|c|c|c|c|c|c|c|}
\hline \multicolumn{8}{|c|}{$\operatorname{Model}^{\mathrm{a}}: Y_{i}=\beta_{0}+\beta_{1} x_{i N-\text { rate }}+\beta_{2} x_{i N-\text { rate }}^{2}+\beta_{3} x_{\text {istage }}+\beta_{4} x_{\text {istage }}^{2}+\varepsilon_{i}$} \\
\hline Index & F-statistic & N-rate & N-rate ${ }^{2}$ & Stage & Stage $^{2}$ & MSE & $\mathrm{R}_{\text {adjusted }} 2 \mathrm{~b}$ \\
\hline \multicolumn{8}{|c|}{ Cotton Plant $^{\mathrm{c}}$} \\
\hline NDVI & $* * *$ & $* *$ & $*$ & $* * *$ & $* * *$ & 0.002 & 0.79 \\
\hline GNDVI & $* * *$ & $* * *$ & $* * *$ & $* * *$ & $* * *$ & 0.001 & 0.88 \\
\hline RENDVI & $* * *$ & $* * *$ & $* *$ & $* * *$ & $* * *$ & 0.002 & 0.85 \\
\hline NAVI & $* * *$ & $*$ & NS & $* * *$ & $* * *$ & 0.001 & 0.76 \\
\hline $\mathrm{CI}_{\text {green }}$ & $* * *$ & $* * *$ & $* * *$ & $* * *$ & $* * *$ & 1.205 & 0.85 \\
\hline TGI & $* * *$ & $* * *$ & $*$ & $* * *$ & $* * *$ & 0.585 & 0.53 \\
\hline \multicolumn{8}{|l|}{ Helena $^{\mathrm{d}}$} \\
\hline NDVI & $* * *$ & $* * *$ & $* * *$ & $-^{\mathrm{e}}$ & - & 0.000 & 0.70 \\
\hline GNDVI & $* * *$ & $* * *$ & $* * *$ & - & - & 0.000 & 0.78 \\
\hline RENDVI & $* * *$ & $* * *$ & $* * *$ & - & - & 0.001 & 0.81 \\
\hline NAVI & $* * *$ & $* * *$ & $* * *$ & - & - & 0.000 & 0.69 \\
\hline $\mathrm{CI}_{\text {green }}$ & $* * *$ & $* * *$ & $* * *$ & - & - & 0.739 & 0.79 \\
\hline TGI & $* * *$ & $* * *$ & $* * *$ & - & - & 0.162 & 0.69 \\
\hline
\end{tabular}

${ }^{a}$ Multiple linear regression of index value $\left(Y_{i}\right)$ with nitrogen rate $\left(\mathrm{x}_{\mathrm{i} \text { N-Rate. }}\right)$ and stage terms $\left(\mathrm{x}_{\mathrm{i} \text { stage }}\right)$

${ }^{\mathrm{b}}$ Model fit assessment was performed using Adjusted Coefficient of Determination

${ }^{\mathrm{c}}$ Remote sensing imagery at Cotton Plant was collected weekly between V6 and R4 with 108 observations per index

${ }^{\mathrm{d}}$ Remote sensing imagery at Helena was collected monthly; only data at R2 (18 observations per index) was available

${ }^{\mathrm{e}} \mathrm{A}$ dash (-) denotes that the parameter was not included because only a single growth stage observation was available

$*, * *, * * *$ significant at the $0.05,0.01,0.001$ probability levels respectively. Otherwise not significant (NS)

control for any heteroscedasticity present in the data. Heteroscedasticity consistent standard errors were calculated using the White (HC1) method (White, 1980):

$$
y_{i}=\beta_{0}+\beta_{1} x_{\text {iindex }}+\varepsilon_{i},
$$

where $y_{i}$ is the maize grain yield and $x_{\text {iindex }}$ is the index value.

\section{Saturation analysis}

The ability of an index to distinguish among $\mathrm{N}$-fertilizer rate treatments was evaluated using a general linear model (GLM). Factor level (N-rate) analysis was performed using a Dunnett's T-test. Index values for each $\mathrm{N}$-rate was compared to index values obtained from the control $\mathrm{N}$-rate (247 $\mathrm{kg} \mathrm{N} \mathrm{ha}^{-1}$ ) (Eq. 3). The relationship between maize grain yield and $\mathrm{N}$-fertilizer rate was also analyzed using a GLM and Dunnett's T-test with the same control N-rate of $247 \mathrm{~kg} \mathrm{~N} \mathrm{ha}^{-1}$ (Eq. 4). Familywise error rates were controlled at $\alpha \leq 0.05$ for both models.

$$
y_{\text {iindex }}=\beta_{0}+\beta_{1} x_{i N-\text { rate }}+\varepsilon_{i},
$$

where $y_{\text {iindex }}$ is the index value and $x_{i N \text {-rate }}$ is the nitrogen application rate. 
Table 6 Summary of results using a regression model with maize grain yield as a function of vegetation index value
Prediction of yield by remote sensing index

Model $^{\mathrm{a}}: Y_{i}=\beta_{0}+\beta_{1} x_{\text {index }}+\varepsilon_{i}$

\begin{tabular}{l} 
Index ${ }^{\mathrm{b}}$ \\
\hline Cotton Plant: V6 growth stage \\
NDVI \\
RENDVI \\
GNDVI \\
NAVI \\
CI $_{\text {green }}$ \\
TGI \\
Cotton Plant: V7 growth stage \\
NDVI \\
RENDVI \\
GNDVI \\
NAVI \\
CI ${ }_{\text {green }}$ \\
TGI
\end{tabular}

Cotton Plant: V8 growth stage

NDVI
RENDVI
GNDVI
NAVI
CI $_{\text {green }}$
TGI

$\mathrm{P}$ value: $\beta_{1}$

MSE

$\mathrm{R}^{2}$

$\begin{array}{lrr}\text { NS } & 11.391 & 0.07 \\ * & 9.378 & 0.24 \\ * & 9.302 & 0.24 \\ \text { NS } & 11.417 & 0.07 \\ * & 8.735 & 0.29 \\ * & 9.406 & 0.24\end{array}$

* $\quad 8.521 \quad 0.31$

*** $\quad 3.956 \quad 0.68$

$\begin{array}{lll}* * * & 3.537 & 0.71\end{array}$

$\begin{array}{lll}* & 8.940 & 0.27\end{array}$

*** $\quad 2.775 \quad 0.77$

$\begin{array}{lll}* & 7.997 & 0.35\end{array}$

Cotton Plant: R2 growth stage

NDVI

*** $\quad 2.175 \quad 0.82$

*** $\quad 0.432 \quad 0.96$

RENDVI

$0.580 \quad 0.95$

GNDVI

NAVI

$2.320 \quad 0.81$

$\mathrm{CI}_{\text {green }}$

$0.246 \quad 0.98$

TGI

$1.039 \quad 0.92$

Helena: R2 growth stage

\begin{tabular}{llll} 
NDVI & $* * *$ & 0.139 & 0.96 \\
RENDVI & $* * *$ & 0.200 & 0.94 \\
GNDVI & $* * *$ & 0.120 & 0.96 \\
NAVI & $* * *$ & 0.144 & 0.96 \\
CI $_{\text {green }}$ & $* * *$ & 0.128 & 0.96 \\
TGI & $* * *$ & 0.326 & 0.90 \\
\hline
\end{tabular}

${ }^{a}$ Analysis was performed using simple linear regression of maize grain yield $\left(Y_{i}\right)$ by index value $\left(x_{i \text { index }}\right)$

${ }^{\mathrm{b}}$ Remote sensing imagery was collected weekly at Cotton Plant, monthly at Helena. 18 observations were made per index, per site, per growth stage

$*, * *, * * *$ significant at the $0.05,0.01,0.001$ probability levels respectively. Otherwise not significant (NS) 


$$
y_{\text {iyield }}=\beta_{0}+\beta_{1} x_{\text {iN-rate }}+\varepsilon_{i}
$$

where $y_{\text {iyield }}$ is the maize grain yield and $x_{i N-\text { rate }}$ is the nitrogen application rate.

This factor-level analysis demonstrates the ability of each vegetation index to distinguish N-rate treatments from the $247 \mathrm{~kg} \mathrm{~N} \mathrm{ha}^{-1}$ control. Vegetation index or crop yield saturation occurs when they become insensitive to additional $\mathrm{N}$-application (Maresma et al., 2018). Ideally, a vegetation index will become saturated at the same (or greater) N-rate as yield. When a vegetation index and yield become saturated at the same N-rate, the index is determined to have a strong sensitivity to $\mathrm{N}$-deficiency in maize.

\section{Results}

\section{Relationship among $\mathrm{N}$-rate, stage and index values}

At Cotton Plant, GNDVI was found to have the highest $\mathrm{R}^{2}$ adj. value $(0.88)$ followed by $\mathrm{CI}_{\text {green }}\left(\mathrm{R}^{2}{ }_{\text {adj }}=0.85\right)$ and RENDVI $\left(\mathrm{R}^{2}{ }_{\text {adj }}=0.85\right)$ when index was modeled as a quadratic function of N-rate and growth stage (growth stages ranging between V6 and R4 (Table 5). At Helena, a quadratic model with index as a function of N-rate indicated RENDVI to have the highest $\mathrm{R}_{\text {adj }}^{2}$ value $(0.81)$ followed by $\mathrm{CI}_{\text {green }}\left(\mathrm{R}_{\text {adj }}^{2}=0.79\right)$ and GNDVI $\left(\mathrm{R}_{\mathrm{adj}}^{2}=0.78\right)$. Stage was not parametrized at Helena because data was only available at the $\mathrm{R} 2$ growth stage (kernel blister stage). Stage and N-rate variables explained more variation in GNDVI, $\mathrm{CI}_{\text {green }}$ and RENDVI than in TGI, NAVI and NDVI at both sites (Table 5).

\section{Relationship between maize grain yield and vegetation indices during vegetative growth stages}

At the V6 growth stage, $\mathrm{CI}_{\text {green }}$ had the best relationship with yield $\left(\mathrm{R}^{2}=0.29\right)$ followed by GNDVI $\left(\mathrm{R}^{2}=0.24\right)$ and RENDVI $\left(\mathrm{R}^{2}=0.24\right.$; Table 6$)$. This same ranking was preserved at the V7 growth stage, but with stronger relationships: $\mathrm{CI}_{\text {green }}\left(\mathrm{R}^{2}=0.77\right)>\mathrm{GNDVI}$ $\left(\mathrm{R}^{2}=0.71\right)>\mathrm{RENDVI}\left(\mathrm{R}^{2}=0.68\right)$. At the $\mathrm{V} 8$ growth stage, the relationship between yield and index strengthened, but index rankings changed: GNDVI $\left(\mathrm{R}^{2}=0.89\right)=\mathrm{CI}_{\text {green }}$ $\left(\mathrm{R}^{2}=0.89\right)>\mathrm{RENDVI}\left(\mathrm{R}^{2}=0.84\right)$. For all indices, the relationship between maize grain yield and reflectance collected during vegetative growth strengthened as the season progressed. Even though the rankings changed slightly over time, the same three indices $\left(\mathrm{CI}_{\text {green }}, \mathrm{GNDVI}\right.$ and RENDVI) remained the strongest throughout vegetative growth (Table 6).

\section{Sensitivity/distinguishing capability of each index during vegetative growth stages}

As the maize crop developed, the distinguishing capabilities and saturation points of each index increased (Table 7). At the V6 growth stage, only TGI distinguished any of the different $\mathrm{N}$-fertilizer rates from the control $\left(247 \mathrm{~kg} \mathrm{~N} \mathrm{ha}^{-1}\right)$. By the $\mathrm{V} 7$ growth stage, RENDVI, GNDVI and $\mathrm{CI}_{\text {green }}$ were able to differentiate the $0 \mathrm{~kg} \mathrm{~N} \mathrm{ha}^{-1}$ and $62 \mathrm{~kg} \mathrm{~N} \mathrm{ha}^{-1}$ treatments from the control $(\alpha<0.05)$. Triangle greenness index could distinguish between $62 \mathrm{~kg} \mathrm{~N} \mathrm{ha}^{-1}$ and the control $(\alpha<0.05)$. At the V8 growth stage, $\mathrm{CI}_{\text {green }}$, RENDVI and GNDVI were still only able to differentiate between the control treatment and N-rates up 
Table 7 Factor level analysis of vegetation indices and maize grain yield

\begin{tabular}{|c|c|c|c|c|c|c|}
\hline \multicolumn{7}{|c|}{$\operatorname{Model}^{\mathrm{a}}: Y_{i}=\beta_{0}+\beta_{1} x_{i N-\text { rate }}+\varepsilon_{i}$} \\
\hline \multirow[t]{3}{*}{ Dependent variable } & \multicolumn{6}{|c|}{ Nitrogen treatment } \\
\hline & \multicolumn{6}{|c|}{$\mathrm{kg} \mathrm{N} \mathrm{ha}^{-1}$} \\
\hline & 0 & 62 & 124 & 185 & 247 & 309 \\
\hline \multicolumn{7}{|c|}{ Cotton Plant: V6 growth stage } \\
\hline NDVI & NS & NS & NS & NS & Control & NS \\
\hline RENDVI & NS & NS & NS & NS & Control & NS \\
\hline GNDVI & NS & NS & NS & NS & Control & NS \\
\hline NAVI & NS & NS & NS & NS & Control & NS \\
\hline $\mathrm{CI}_{\text {green }}$ & NS & NS & NS & NS & Control & NS \\
\hline TGI & NS & $*$ & NS & NS & Control & NS \\
\hline \multicolumn{7}{|c|}{ Cotton Plant: V7 growth stage } \\
\hline NDVI & NS & NS & NS & NS & Control & NS \\
\hline RENDVI & $* *$ & $*$ & NS & NS & Control & NS \\
\hline GNDVI & $* *$ & $*$ & NS & NS & Control & NS \\
\hline NAVI & NS & NS & NS & NS & Control & NS \\
\hline $\mathrm{CI}_{\text {green }}$ & $* *$ & $*$ & NS & NS & Control & NS \\
\hline TGI & NS & $*$ & NS & NS & Control & NS \\
\hline \multicolumn{7}{|c|}{ Cotton Plant: V8 growth stage } \\
\hline NDVI & $*$ & NS & NS & NS & Control & NS \\
\hline RENDVI & $* * *$ & $* *$ & NS & NS & Control & NS \\
\hline GNDVI & $* * *$ & $* * *$ & NS & NS & Control & NS \\
\hline NAVI & NS & NS & NS & NS & Control & NS \\
\hline $\mathrm{CI}_{\text {green }}$ & $* * *$ & $* * *$ & NS & NS & Control & NS \\
\hline TGI & NS & $* *$ & NS & NS & Control & NS \\
\hline \multicolumn{7}{|c|}{ Cotton Plant: R2 growth stage } \\
\hline NDVI & $* * *$ & $* *$ & NS & NS & Control & NS \\
\hline RENDVI & $* * *$ & $* * *$ & $* *$ & NS & Control & NS \\
\hline GNDVI & $* * *$ & $* * *$ & $*$ & NS & Control & NS \\
\hline NAVI & $* *$ & $*$ & NS & NS & Control & NS \\
\hline $\mathrm{CI}_{\text {green }}$ & $* * *$ & $* * *$ & $* *$ & NS & Control & NS \\
\hline TGI & $* * *$ & $* * *$ & NS & NS & Control & NS \\
\hline \multicolumn{7}{|c|}{ Cotton Plant: maize grain yield } \\
\hline Grain yield & $* * *$ & $* * *$ & $* * *$ & NS & Control & NS \\
\hline \multicolumn{7}{|c|}{ Helena: R2 growth stage } \\
\hline NDVI & $* * *$ & NS & NS & NS & Control & NS \\
\hline RENDVI & $* * *$ & NS & NS & NS & Control & NS \\
\hline GNDVI & $* * *$ & NS & NS & NS & Control & NS \\
\hline NAVI & $* * *$ & NS & NS & NS & Control & NS \\
\hline $\mathrm{CI}_{\text {green }}$ & $* * *$ & NS & NS & NS & Control & NS \\
\hline TGI & $* *$ & NS & NS & NS & Control & NS \\
\hline \multicolumn{7}{|c|}{ Helena: maize grain yield } \\
\hline Grain yield & $* * *$ & NS & NS & NS & Control & NS \\
\hline
\end{tabular}

${ }^{\text {a }}$ Dunnett's t-test used for factor level analysis.

${ }^{\mathrm{b}}$ University of Arkansas recommended rate is the control nitrogen rate. $*$, **,*** significant at the $0.05,0.01,0.001$ and probability levels respectively. Otherwise not significant (NS) 
to $62 \mathrm{~kg} \mathrm{~N} \mathrm{ha}^{-1}$, but with greater confidence $(\mathrm{P}<0.01)$. During vegetative growth stages (Cotton Plant), no index was able to differentiate between the control and the $\mathrm{N}$-fertilizer rates with the same sensitivity as grain yield. Grain yield was responsive to $\mathrm{N}$-application up to $124 \mathrm{~kg} \mathrm{~N} \mathrm{ha}^{-1}$, but index saturation consistently occurred at $62 \mathrm{~kg} \mathrm{~N} \mathrm{ha}^{-1}$ (V7 and V8 growth stages) for the top performing indices.

\section{Relationship between maize grain yield and vegetation indices at the R2 growth stage}

When limiting the analysis to only observations at the $\mathrm{R} 2$ growth stage, $\mathrm{CI}_{\text {green }}$ had the strongest relationship with maize grain yield at Cotton Plant $\left(\mathrm{R}^{2}=0.98\right.$; Table 6$)$. Red-edge NDVI $\left(\mathrm{R}^{2}=0.96\right)$ and GNDVI $\left(\mathrm{R}^{2}=0.95\right)$ closely followed $\mathrm{CI}_{\text {green }}$ in terms of predicting grain yield. Similar results were observed at Helena at the R2 growth stage where GNDVI, $\mathrm{CI}_{\text {green }}$ and NDVI all had a strong relationship with grain yield $\left(\mathrm{R}^{2}=0.96\right)$. The remaining indices had significant relationships with yield $\left(\mathrm{R}^{2} \geq 0.89\right.$; Table 6$)$.

\section{Sensitivity/distinguishing capability of each index during the $\mathbf{R} 2$ growth stage}

Increased predictive power from later image acquisition allowed RENDVI, GNDVI, $\mathrm{CI}_{\text {green }}$ and TGI to differentiate among $\mathrm{N}$-fertilizer rate treatments and the control with a sensitivity similar to grain yield (Table 7). At Helena, all indices distinguished between the control and $\mathrm{N}$-rate treatments with a precision similar to grain yield. At Cotton Plant, RENDVI, GNDVI and $\mathrm{CI}_{\text {green }}$ also demonstrated a sensitivity similar to grain yield. This relationship was not replicated at Cotton Plant with NDVI, NAVI and TGI.

\section{Discussion}

The growth stage of maize had a significant effect on index values (Table 5), suggesting that models used to predict $\mathrm{N}$-demand must account for growth stage at the time of data collection. Otherwise, data collection must occur at a specific maize growth stage to obtain comparable results across sites. Depending on the crop's maturity when imagery is captured, remote sensing data can be used in one of two manners: ex post facto (retrospective analysis of $\mathrm{N}$-supply) and ex ante facto (concurrent analysis of $\mathrm{N}$-supply).

\section{Remote sensing during vegetative growth stages}

\section{Prediction of maize grain yield by vegetation indices}

The utility of remotely sensed multispectral vegetation indices for in-season N-management (ex ante facto analysis) is dependent on their performance during the early stages of crop development. It is during these stages that fertilizer and irrigation management practices can be adjusted (Joshi et al., 2019). These results agree with Teal et al. (2006) who found that relationships with maize grain yield strengthened rapidly between V6 and V8 (Table 6). Likewise, Olson et al. (2019) found $\mathrm{R}^{2}$ values for maize gain yield:RENDVI to increase as the season progressed. Increased predictive power may be the result of decreased soil background or a greater proportion of $\mathrm{N}$-deficiency having been realized as 
the season progressed (Corti et al., 2019). By the V8 stage, the regression models explained 89,88 and $83 \%$ of the maize grain yield variance for $\mathrm{CI}_{\text {green }}$, GNDVI and RENDVI respectively (Table 6). Early-season sensitivity of $\mathrm{CI}_{\text {green }}$ was also observed by Hatfield and Prueger (2010), who found $\mathrm{CI}_{\text {green }}$ to be more sensitive than the normalized pigment chlorophyll ratio index early in the season.

\section{Sensitivity of remote sensing indices}

Ideally, an index will fail to incur significant differences relative to the control treatment at or above the factor level where yield becomes unresponsive to additional N-supply. In this study, all indices failed to demonstrate a sensitivity similar to yield, at or prior to, the V8 growth stage (Table 7). Although severe $\mathrm{N}$-deficiencies were detected by $\mathrm{CI}_{\text {green }}$, GNDVI and RENDVI, slight N-deficiency, capable of causing yield loss, remained undetected. Therefore, remote sensing with these indices during vegetative growth stages may overlook agronomically-significant N-deficiency. However, deficiency of a large magnitude may be discernible using $\mathrm{CI}_{\text {green, }}$ GNDVI or RENDVI.

\section{Potential application}

At the V8 growth stage, the three best performing indices $\left(\mathrm{CI}_{\text {green }}\right.$, RENDVI and GNDVI) all had relatively wide prediction intervals of $\pm 2.5,3.1$ and $\mathrm{tha}^{-1}$ grain yield, respectively. Additionally, the index's relationship with yield and the time window for sidedress N-application were inversely related. As the index's predictive power increased, the opportunity to sidedress nitrogen decreased simultaneously because of increasing maize height. The relationship between growth stage and model variability creates an optimization problem where minimizing model variability will be hindered by $\mathrm{N}$-sidedress timing constraints.

The combination of timing (crop stage and $\mathrm{N}$-application constraints) and wide prediction intervals (variability) may hinder in-season $\mathrm{N}$-adjustments based on remote sensing as described by Clay et al. (2006). In their 2006 study, they suggested that remotely sensed $\mathrm{N}$-demand could be used to calculate nitrogen credits Eq. (5):

$$
N \sim \text { demand }=(0.021 \times \text { optimal yield })-(\text { remote sensing predicted yield })
$$

They further suggested that nitrogen credits calculated via remote sensing may be an improvement on simple yield-based recommendations.

The findings suggest that, unless $\mathrm{N}$-sidedress occurs late in the growing season, variability in yield by index regressions during vegetative growth may impede remote sensing-based N-credits. Nitrogen controls or "ramps" may be necessary to account for site, year and cultivar effects (Dellinger et al., 2008; Maresma et al., 2018; Olson et al., 2019; Schmidt et al., 2009). When these effects are controlled, EONRs can be predicted by GNDVI during vegetative growth stages (Dellinger et al., 2008; Schmidt et al., 2009).

Despite limitations concerning sensitivity, predictive power and significant growth stage effects, chlorophyll indices may still be a pragmatic N-management tool without requiring further adjustments. Because the index values had lower $\mathrm{N}$-saturation points than yield (Table 7), yield reduction can occur without a corresponding change in index values. When index values differed among treatments, maize grain yield was significantly different. Therefore, a significant difference in index values between $\mathrm{N}$-deficient and $\mathrm{N}$-sufficient maize will likely correspond with grain yield loss. 
These latter principles may be applied to scenarios where N-dynamics have undergone radical alteration. For instance, remote sensing after a flood may be a niche where UASbased adjustments would be beneficial (Hunt \& Daughtry, 2018). In this scenario, farmers or crop consultants could detect areas where persistent saturation has increased denitrification, leaching or reduced the maize stand count. Appropriate remediation strategies, such as applying additional $\mathrm{N}$-fertilizer, could then be implemented to minimize yield loss (Hunt \& Daughtry, 2018).

\section{Improving remote sensing sensitivity and decreasing variance in $\mathrm{N}$-deficient maize}

Several techniques are available that may assist with the detection of $\mathrm{N}$-stress and reduce index variability during the vegetative growth stages. First, maize grain yield by NDVI index regressions can be improved between V7 and V9 if growing degree days are included in regression models. Prior to V8, yield potential is not fully developed, which introduces variability (Teal et al., 2006). Second, the relationship between the predictive power of chlorophyll indices and yield increases with maize growth stage progression. Therefore, remote sensing data acquisition should be performed as late as possible (i.e. late vegetative or early reproductive stages) for optimal sensitivity. Finally, adjusting index values to account for soil background can significantly improve the predictive power (Corti et al., 2019).

Reese et al. (2010) came to a similar conclusion for hard red wheat. They found that waiting until later crop development stages minimized soil interference and reduced variability. However, this may not be applicable to all indices. Because some indices, like NDVI, are primarily determined by leaf to soil ratio, they may be less reliable late in the season once canopy closure has occurred (Sharma et al., 2015). This was observed by Olson et al. (2019), who found maize grain yield by NDVI regressions had $\mathrm{R}^{2}$ values ranging from 0 to 0.69 at the R1 (silk) growth stage. Using the same growth stage and statistical model, RENDVI had $\mathrm{R}^{2}$ values ranging from 0.74 to 0.79 .

\section{Remote sensing during early reproductive growth stages}

\section{Prediction of maize grain yield by vegetation indices}

The relationship between index values and maize grain yield was stronger at the R2 growth stage than at V8 for all indices studied (Table 6). Even NDVI performed well at the later stages of maize growth and development. The $\mathrm{R}^{2}$ value for maize grain yield as a function of NDVI at R2 was 0.82 and 0.96 respectively at the Cotton Plant and Helena locations. This suggests that canopy closure may have been incomplete (Hatfield \& Prueger, 2010; Teal et al., 2006).

Chlorophyll indices performed well overall. At both sites, the relationship between RENDVI, GNDVI, $\mathrm{CI}_{\text {green }}$ and grain yield produced $\mathrm{R}^{2}$ values greater than 0.93 . The high correlation between maize-grain yield and index values during the early reproductive stages is supported by other recent studies. For example, Olson et al., (2019) found RENDVI to best predict maize grain yield during the R1 growth stage in a study in western Minnesota. Results from other growth stages (V4 to R4) showed significantly weaker correlations compared to the R1 growth stage. Preza Fontes et al. (2019) found that the correlation between maize grain yield and NDVI increased as the season progressed, and the maize entered the R1 growth stage. Likewise, Shanahan et al. (2001) observed a strong 
correlation between GNDVI captured during mid-grain fill and yield $(r=0.70$ and 0.92 during the 1997 and 1998 cropping seasons respectively). Like the findings at the Cotton Plant site, correlation coefficients for NDVI were significantly lower than GNDVI at the same growth stage.

\section{Sensitivity of remote sensing indices}

At R2, $\mathrm{CI}_{\text {Green }}$, RENDVI and GNDVI had saturation points similar to maize gain yield across all sites in the current study. However, at Cotton Plant, NDVI, NAVI and TGI failed to demonstrate a sensitivity similar to yield, whereas these three indices did demonstrate sensitivity to yield at Helena at R2, similar to the other indices (Table 7). Although $\mathrm{N}$-application during early reproductive stages may not be practical, $\mathrm{CI}_{\text {green }}, \mathrm{RENDVI}$ and GNDVI may still be useful in ex post-facto assessments of grain yield and $\mathrm{N}$-supply, possibly providing a retrospective assessment.

\section{Potential application}

Shanahan et al. (2001) suggested GNDVI measurements made during maize grain fill as a possible alternative to combine generated yield maps. It has been estimated that only $50 \%$ of maize farmers utilize georeferenced grain yield monitoring, which can increase profits by almost 3\% (Schimmelpfennig, 2016). Small-scale (<1 174 ha) maize farmers are less likely to adopt georeferenced grain yield monitoring than farmers with acreage greater than 1174 ha. Ex post-facto analysis may be a critical management tool for farmers who have not invested in yield monitors, but desire yield maps for certain fields.

Due to the high N-leaching potential of sandy soils, N-deficiency is more common on coarse-textured soils than on fine-textured soils. Ex post-facto analysis may allow interspersed sandy locations to be delineated. This would allow estimates to be made of the severity of the N-stress during the past season relative to high yielding portions of the field.

\section{Conclusions}

All six remote sensing indices evaluated had significant relationships with $\mathrm{N}$-fertilizer rate and maize growth stage when analyzed using multiple linear regression models. The predictive power of the models evaluated increased when the remote sensing data were collected later in the growing season. The ability of the indices to distinguish various N-rate treatments from the $\mathrm{N}$-sufficient control treatment also increased during the later stages of development. Across all study sites and stages, $\mathrm{CI}_{\text {green }}$, GNDVI and RENDVI demonstrated the greatest reliability for detecting $\mathrm{N}$-deficiency in maize. Overall, $\mathrm{CI}_{\text {green }}$, RENDVI and GNDVI may prove to be valuable tools for $\mathrm{N}$-management.

Any attempt to use remote sensing to predict yield differences due to $\mathrm{N}$-stress in maize must account for several factors, especially maize growth stage. Additionally, site, year, cultivar, tillage system and various agronomic stresses may affect plant reflectance. These variables must be controlled either by $\mathrm{N}$-sufficient control strips or additional site-specific yield modeling that incorporates remote sensing data Future studies that incorporate LAI measurements, multiple study sites in multiple locations and harvest yield monitor data are recommended in order to enhance understanding of remote sensing utilization for $\mathrm{N}$ management. 
Author contributions All authors contributed to the study conception and design. Field management was performed by VSG, JHM and BWB. Remote sensing data collection and analysis was performed by BWB and AAH. Statistical analysis and modeling were performed by BWB, MM and AMS, MAAA-B provided significant contribution in plant and soil nitrogen dynamics. The first draft of the manuscript was written by BWB and all authors commented on previous versions of the manuscript. All authors read and approved the final manuscript.

Funding This research was funded in part by a United States Department of Agriculture-NRCS Arkansas Conservation Innovations Grant (\#68-7103-18-004) and United States Department of AgricultureNIFA Grant (\#2018-70001-27817) along with support from the University of Arkansas System Division of Agriculture.

Data availability The datasets generated during and/or analyzed during the current study are available from the corresponding author on reasonable request.

\section{Declarations}

Conflict of interest The authors declare that they have no conflict of interest.

Open Access This article is licensed under a Creative Commons Attribution 4.0 International License, which permits use, sharing, adaptation, distribution and reproduction in any medium or format, as long as you give appropriate credit to the original author(s) and the source, provide a link to the Creative Commons licence, and indicate if changes were made. The images or other third party material in this article are included in the article's Creative Commons licence, unless indicated otherwise in a credit line to the material. If material is not included in the article's Creative Commons licence and your intended use is not permitted by statutory regulation or exceeds the permitted use, you will need to obtain permission directly from the copyright holder. To view a copy of this licence, visit http://creativecommons.org/licenses/by/4.0/.

\section{References}

Carmona, F., Rivas, R., \& Fonnegra, D. C. (2015). Vegetation Index to estimate chlorophyll content from multispectral remote sensing data. European Journal of Remote Sensing, 48(1), 319-326. https://doi. org/10.5721/EuJRS20154818

Clay, D. E., Kim, K.-I., Chang, J., Clay, S. A., \& Dalsted, K. (2006). Characterizing water and nitrogen stress in corn using remote sensing. Agronomy Journal, 98(3), 579-587. https://doi.org/10.2134/agron j2005.0204

Corti, M., Cavalli, D., Cabassi, G., Vigoni, A., Degano, L., \& Gallina, P. (2019). Application of a low-cost camera on a UAV to estimate maize nitrogen-related variables. Precision Agriculture, 20(4), 675-696. https://doi.org/10.1007/s11119-018-9609-y

Delegido, J., Vergara, C., Verrelst, J., Gandía, S., \& Moreno, J. (2011). Remote estimation of crop chlorophyll content by means of high-spectral-resolution reflectance techniques. Agronomy Journal, 103(6), 1834-1842. https://doi.org/10.2134/agronj2011.0101

Dellinger, A. E., Schmidt, J. P., \& Beegle, D. B. (2008). Developing nitrogen fertilizer recommendations for corn using an active sensor. Agronomy Journal, 100(6), 1546. https://doi.org/10.2134/agronj2007.0386

Dhital, S., \& Raun, W. R. (2016). Variability in optimum nitrogen rates for maize. Agronomy Journal, 108(6), 2165-2173. https://doi.org/10.2134/agronj2016.03.0139

Doran, J. W. (1987). Microbial biomass and mineralizable nitrogen distributions in no-tillage and plowed soils. Biology and Fertility of Soils, 5(1), 68-75. https://doi.org/10.1007/BF00264349

English, E., Ketterings, Q., Czymmek, K., Gabriel, A., Flis, F., \& Lawrence, J. (2017). Nitrogen uptake by corn. Cornell University Cooperative Extension, Agronomy Fact Sheet Series (Fact Sheet \#98), 1-2.

Espinoza, L. \& Ross, J. (2012). Fertilization and liming. In L. Espinoza \& J. Ross (Eds.), Corn Production Handbook (MP437). Retrieved September 9, 2021, from https://www.uaex.edu/publications/pdf/ mp437/mp437.pdf

Friedman, J. M., Hunt, E. R., \& Mutters, R. G. (2016). Assessment of leaf color chart observations for estimating maize chlorophyll content by analysis of digital photographs. Agronomy Journal, 108(2), 822-829. https://doi.org/10.2134/agronj2015.0258 
Gabriel, J. L., Alonso-Ayuso, M., García-González, I., Hontoria, C., \& Quemada, M. (2016). Nitrogen use efficiency and fertiliser fate in a long-term experiment with winter cover crops. European Journal of Agronomy, 79, 14-22. https://doi.org/10.1016/j.eja.2016.04.015

Gautam, D., \& Pagay, V. (2020). A Review of current and potential applications of remote sensing to study the water status of horticultural crops. Agronomy, 10(1), 140. https://doi.org/10.3390/agronomy 10 010140

Gitelson, A., \& Merzlyak, M. N. (1994). Quantitative estimation of chlorophyll-a using reflectance spectra: Experiments with autumn chestnut and maple leaves. Journal of Photochemistry and Photobiology B: Biology, 22(3), 247-252. https://doi.org/10.1016/1011-1344(93)06963-4

Gitelson, A., Viña, A., Ciganda, V., Rundquist, D., \& Arkebauer, T. (2005). Remote estimation of canopy chlorophyll content in crops. Geophysical Research Letters, 32(8), L08403. https://doi.org/10. 1029/2005GL022688

Gitelson, A. A. (2005). Remote estimation of canopy chlorophyll content in crops. Geophysical Research Letters, 32(8), L08403. https://doi.org/10.1029/2005GL022688

Gitelson, A. A., \& Merzlyak, M. N. (1997). Remote estimation of chlorophyll content in higher plant leaves. Remote Sensing, 18(12), 2691-2697.

Gitelson, A. A., Gritz, Y., \& Merzlyak, M. N. (2003). Relationships between leaf chlorophyll content and spectral reflectance and algorithms for non-destructive chlorophyll assessment in higher plant leaves. Journal of Plant Physiology, 160(3), 271-282. https://doi.org/10.1078/0176-1617-00887

Hatfield, J. L., \& Prueger, J. H. (2010). Value of using different vegetative indices to quantify agricultural crop characteristics at different growth stages under varying management practices. Remote Sensing, 2(2), 562-578. https://doi.org/10.3390/rs2020562

Hunt, E. R., \& Daughtry, C. S. T. (2018). What good are unmanned aircraft systems for agricultural remote sensing and precision agriculture? International Journal of Remote Sensing, 39(15-16), 5345-5376. https://doi.org/10.1080/01431161.2017.1410300

Hunt, E. R., Daughtry, C. S. T., Eitel, J. U. H., \& Long, D. S. (2011). Remote sensing leaf chlorophyll content using a visible band index. Agronomy Journal, 103(4), 1090-1099. https://doi.org/10.2134/ agronj2010.0395

Hunt, E. R., Doraiswamy, P. C., McMurtrey, J. E., Daughtry, C. S. T., Perry, E. M., \& Akhmedov, B. (2013). A visible band index for remote sensing leaf chlorophyll content at the canopy scale. International Journal of Applied Earth Observation and Geoinformation, 21, 103-112. https://doi.org/ 10.1016/j.jag.2012.07.020

Joshi, V. R., Thorp, K. R., Coulter, J. A., Johnson, G. A., Porter, P. M., Strock, J. S., et al. (2019). Improving site-specific maize yield estimation by integrating satellite multispectral data into a crop model. Agronomy, 9(11), 719. https://doi.org/10.3390/agronomy9110719

Kaspar, T. C., Jaynes, D. B., Parkin, T. B., Moorman, T. B., \& Singer, J. W. (2012). Effectiveness of oat and rye cover crops in reducing nitrate losses in drainage water. Agricultural Water Management, 110, 25-33. https://doi.org/10.1016/j.agwat.2012.03.010

Kuo, S., Huang, B., \& Bembenek, R. (2001). Effect of winter cover crops on soil nitrogen availability, corn yield, and nitrate leaching. The Scientific World Journal, 1, 22-29. https://doi.org/10.1100/ tsw. 2001.267

Mahajan, G. R., Sahoo, R. N., Pandey, R. N., Gupta, V. K., \& Kumar, D. (2014). Using hyperspectral remote sensing techniques to monitor nitrogen, phosphorus, sulphur and potassium in wheat (Triticum aestivum L.). Precision Agriculture, 15(5), 499-522. https://doi.org/10.1007/ s11119-014-9348-7

Mahal, N. K., Castellano, M. J., \& Miguez, F. E. (2018). Conservation agriculture practices increase potentially mineralizable nitrogen: A meta-analysis. Soil Science Society of America Journal, 82(5), 1270-1278. https://doi.org/10.2136/sssaj2017.07.0245

Maresma, Á., Lloveras, J., \& Martínez-Casasnovas, J. (2018). Use of multispectral airborne images to improve in-season nitrogen management, predict grain yield and estimate economic return of maize in irrigated high yielding environments. Remote Sensing, 10(4), 543. https://doi.org/10.3390/rs10040543

Micasense. (n.d.). Altum. Altum (re)defining agricultural drone sensing. Retrieved September 9, 2021, from https://micasense.com/altum/

Morris, T. F., Murrell, T. S., Beegle, D. B., Camberato, J. J., Ferguson, R. B., Grove, J., et al. (2018). Strengths and limitations of nitrogen rate recommendations for corn and opportunities for improvement. Agronomy Journal, 110(1), 1-37. https://doi.org/10.2134/agronj2017.02.0112

NOAA. (n.d.). Climate Data, Des Arc, AR. Retrieved September 9, 2021, from https://www.ncdc.noaa. gov/cdo-web/datasets/GSOM/stations/GHCND:USC00031968/detail

NOAA. (n.d.). Climate Data, Helena, AR. Retrieved September 9, 2021, from https://www.ncdc.noaa. gov/cdo-web/datasets/GSOM/stations/GHCND:USC00033242/detail 
Olson, D., Chatterjee, A., Franzen, D. W., \& Day, S. S. (2019). Relationship of drone-based vegetation indices with corn and sugarbeet yields. Agronomy Journal, 111(5), 2545-2557. https://doi.org/10. 2134/agronj2019.04.0260

Preza Fontes, G., Bhattarai, R., Christianson, L. E., \& Pittelkow, C. M. (2019). Combining environmental monitoring and remote sensing technologies to evaluate cropping system nitrogen dynamics at the field-scale. Frontiers in Sustainable Food Systems, 3, 8. https://doi.org/10.3389/fsufs.2019.00008

Reese, C. L., Long, D., Clay, S., Clay, D., \& Beck, D. (2010). Nitrogen and water stress impacts hard red spring wheat (Triticum aestivum) canopy reflectance. Journal of Terrestrial Observation, 2(1), 21.

Ritchie, S. W., Hanway, J. J., Benson, G. O. (2008). How a corn plant develops (p. 3). Special Report No. 48. Iowa State University Extension, USA.

Rouse, J. W., Haas, R. H., Schell, J. A., Deering, D. W., \& Harlan, J. C. (1974). Monitoring the vernal advnacement and retrogradation (green wave effect) of natural vegetation (pp. 1-164). Remote Sensing Center Texas A\&M University and The Goddard Space Flight Center. College Station, TX, USA. Retrieved October 15, 2020, from https://ntrs.nasa.gov/api/citations/19730017588/downloads/19730 017588.pdf

Schimmelpfennig, D. (2016). Farm profits and adoption of precision agriculture (pp. 1-3). USDA-ERS Economic Research Report Number 217. Retrieved September 9, 2021, from https://www.ers.usda. gov/webdocs/publications/80326/err-217.pdf?v=0

Schmidt, J. P., Dellinger, A. E., \& Beegle, D. B. (2009). Nitrogen recommendations for corn: An on-the-go sensor compared with current recommendation methods. Agronomy Journal, 101(4), 916-924. https:// doi.org/10.2134/agronj2008.0231x

Shanahan, J. F., Schepers, J. S., Francis, D. D., Varvel, G. E., Wilhelm, W. W., Tringe, J. M., et al. (2001). Use of remote-sensing imagery to estimate corn grain yield. Agronomy Journal, 93(3), 583-589. https://doi.org/10.2134/agronj2001.933583x

Sharma, L., Bu, H., Denton, A., \& Franzen, D. (2015). Active-optical sensors using red NDVI compared to red edge NDVI for prediction of corn grain yield in North Dakota, U.S.A. Sensors, 15(11), 2783227853. https://doi.org/10.3390/s151127832

Teal, R. K., Tubana, B., Girma, K., Freeman, K. W., Arnall, D. B., Walsh, O., et al. (2006). In-season prediction of corn grain yield potential using normalized difference vegetation index. Agronomy Journal, 98(6), 1488-1494. https://doi.org/10.2134/agronj2006.0103

Tonitto, C., David, M. B., \& Drinkwater, L. E. (2006). Replacing bare fallows with cover crops in fertilizerintensive cropping systems: A meta-analysis of crop yield and N dynamics. Agriculture, Ecosystems \& Environment, 112(1), 58-72. https://doi.org/10.1016/j.agee.2005.07.003

Tucker, C. J. (1979). Red and photographic infrared linear combinations for monitoring vegetation. Remote Sensing of Environment, 8(2), 127-150. https://doi.org/10.1016/0034-4257(79)90013-0

USDA-ERS. (2019). Fertilizer use and price. Retrieved September 9, 2021, from https://www.ers.usda.gov/ data-products/fertilizer-use-and-price/

USDA-NRCS. (2013). Official soil series descriptions. Convent series. Retrieved September 9, 2021, from https://soilseries.sc.egov.usda.gov/OSD_Docs/C/CONVENT.html

USDA-NRCS. (2019). Official soil series descriptions. Teksob series. Retrieved September 9, 2021, from https://soilseries.sc.egov.usda.gov/OSD_Docs/T/TEKSOB.html

White, H. (1980). A heteroskedasticity-consistent covariance matrix estimator and a direct test for heteroskedasticity. Econometrica, 48(4), 817. https://doi.org/10.2307/1912934

Publisher's Note Springer Nature remains neutral with regard to jurisdictional claims in published maps and institutional affiliations. 


\section{Authors and Affiliations}

\section{Brayden W. Burns ${ }^{1} \cdot$ V. Steven Green ${ }^{2,3}$ (D) Ahmed A. Hashem ${ }^{2,3}$ (D) Joseph H. Massey ${ }^{4}$. Aaron M. Shew ${ }^{2,5,6}$ (D) M. Arlene A. Adviento-Borbe ${ }^{4}$ (D) Mohamed Milad ${ }^{7}$}

1 Environmental Sciences Program, Arkansas State University, Jonesboro, AR, USA

2 College of Agriculture, Arkansas State University, Jonesboro, AR, USA

3 University of Arkansas System Division of Agriculture, Little Rock, AR, USA

4 United States Department of Agriculture-ARS, Delta Water Management Research Unit, Jonesboro, AR, USA

5 Department of Agricultural Economics and Agribusiness, University of Arkansas, Fayetteville, AR, USA

6 Center for Advanced Spatial Technologies, University of Arkansas, Fayetteville, AR, USA

7 Department of Mathematics and Statistics, Arkansas State University, Jonesboro, AR, USA 